\title{
Sulfate and alkali-silica performance of blended cements containing illitic calcined clays
}

\author{
Gisela Cordoba ${ }^{1}$, Agustin Rossetti ${ }^{2}$, Dario Falcone², E.F: Irassar ${ }^{1}$ \\ ${ }^{1}$ Facultad de Ingenieria - CIFICEN (UNCPBA-CICPBA-CONICET), (B7400JWI) Olavarria, \\ Argentina \\ ${ }^{2}$ LEMIT - CIC de la Provincia de Buenos Aires, Av 52 e/121y122, (B1900AYB) La Plata, \\ Argentina
}

\begin{abstract}
Studies of illitic calcined clays are less developed than that corresponding to kaolinitic clays, but illite is one of the more abundant clayed minerals of the earth's crust, as occurs in the Center of the Buenos Aires Province (Argentina) where the largest cement factories are located. Illite clays develop pozzolanic properties when they are thermally treated at $950{ }^{\circ} \mathrm{C}$, causing dehydroxilation and collapse of structure to form a metastable or amorphous aluminosilicate. Illitic calcined clays don't present a significant water demand and the compressive strength of blended cements attains to the corresponding to portland cement at 90 days. It is characterized as slow pozzolana. Illite incorporates certain proportion of reactive alumina and high proportion of alkalis, modifying the pore structure. From durability point of view, the incorporation of illite can affect the sulfate resistance of portland cements or the alkali-silica reaction (ASR).

The aim of this paper is to study the behavior of two different illite calcined clay blended cements against chemical attack, like sulfate attack and harmful alkali silica reaction, using the test based on the ASTM C 1012 and ASTM C 441, respectively. For sulfate performance, illite calcined clays was blended with a low $\mathrm{C}_{3} \mathrm{~A}$ in $20 \%$ and $40 \%$ of weight replacement and a very high $\mathrm{C}_{3} \mathrm{~A}$ cement (white), using a $30 \%$ of weight replacement; while a low $\left(\mathrm{Na}_{2} \mathrm{O}_{\mathrm{eq}}<0.5\right)$ and high alkali $\left(\mathrm{Na}_{2} \mathrm{O}_{\mathrm{eq}}=1.03\right)$ cements were used in the ASR-test.

After six months, the low and very high $\mathrm{C}_{3} \mathrm{~A}$ cements of both illitic clays shows low expansion in sulfate media $(<0.05 \%)$ for blended cement without water demand. The ASR-expansion results show that illitic calcined clays reduce considerably the expansion of high alkali cements and it is not harmful to low alkali cement, but long test time results will be conclusive.
\end{abstract}

\section{Introduction}

Illite is one of the more abundant clayed minerals of the earth's crust coming from the alteration of feldspars and micas of rocks due to the weathering process. Illite clays develop pozzolanic properties when clays are thermally treated at $950{ }^{\circ} \mathrm{C}[1]$ causing dehydroxilation and collapse of structure to form a metastable or amorphous aluminosilicate [2].

Partly substitution of alkali-rich portland cements by calcined clays improves the resistance of the respective concrete against sulfate attack and harmful ASR [3]. It is attributed to the pozzolanic reactivity that consumes the $\mathrm{CH}$ to produce $\mathrm{C}-\mathrm{S}-\mathrm{H}$ and $\mathrm{C}-\mathrm{A}-\mathrm{S}-\mathrm{H}$ causing a denser microstructure due to the pore and grain size refinements $[3,4]$. To controlling ASR, metakaolinite has a very good performance suppressing the expansion. It is attributed to alteration of $\mathrm{C}-\mathrm{S}-\mathrm{H}$ structure, lower $\mathrm{pH}$ in pore solution and $\mathrm{Al}$ absorbed on the surface of reactive silica that slow down the dissolution rate [3, 5]. High resistance to sulfate attack is normally associated with a segmented pore structure and low level of $\mathrm{CH}$. In addition to the role of $\mathrm{CH}$, the reduction of alumina available to suppress ettringite formation is a main factor to improve the resistance to sulfate attack in $\mathrm{Na}_{2} \mathrm{SO}_{4}$ solutions [6].

It is largely documented the durability improvements caused by kaolinitic calcined clays used as replacement of PC, but there is limited information about the performance of other type of clays used as supplementary cementitious materials (SCMs). The aim of this paper is to study the behavior of two illitic calcined clay from the province of Buenos Aires in blended cements against sulfate attack and alkali silica reaction. 


\section{Materials and methods}

Two different illitic clay-stones from quarries near to Olavarria, Buenos Aires Province (Argentine) were reduced to $5 \mathrm{~mm}$ particles and fired in a muffle oven by heating at $10.5^{\circ} \mathrm{C} / \mathrm{min}$ up to $950{ }^{\circ} \mathrm{C}$ and maintaining the maximum temperature during $90 \mathrm{~min}$. Then, samples were cooling down into the oven. Calcined clays were grinding in laboratory ball mill to obtain a $d_{90}$ parameter in the PSD curve lower than $10 \mu \mathrm{m}$. The chemical composition determined by XRF is reported in Table 1 . Both calcined clays meet the chemical requirements for Class N pozzolan (ASTM C 618): $\mathrm{S}+\mathrm{A}+\mathrm{F}>70 \%$; $\mathrm{SO}_{3}<4 \%$ and $\mathrm{LOI}<10 \%$. Calcined clays are identified by their color: Red (R) and Orange (O). XRD analysis reveals low intensity peaks of dehydroxilated illite in both clays and the associated minerals are quartz and hematite for $\mathrm{R}$ calcined clays and, quartz, hematite, oligoclase and spinel for O-Calcined clay. The density (ASTM C 188), retained on 75 and $45 \mu \mathrm{m}$ sieves (ASTM D 422 and C 618), the Blaine specific surface (ASTM C 204) and the particle size distribution (PSD) determined using the laser granulometer (Malvern Mastersizer 2000) are reported in Table 2.

Table 1. Chemical composition and loss on ignition of calcined clays and cements, \%

\begin{tabular}{cccccccccccc}
\hline $\begin{array}{c}\text { Clay/ } \\
\text { Cement }\end{array}$ & $\mathrm{CaO}$ & $\mathrm{SiO}_{2}$ & $\mathrm{Al}_{2} \mathrm{O}_{3}$ & $\mathrm{Fe}_{2} \mathrm{O}_{3}$ & $\mathrm{MgO}$ & $\mathrm{SO}_{3}$ & $\mathrm{~K}_{2} \mathrm{O}$ & $\mathrm{Na}_{2} \mathrm{O}$ & $\mathrm{TiO}_{2}$ & $\mathrm{P}_{2} \mathrm{O}_{5}$ & LOI \\
\hline $\mathrm{R}$ & 0.33 & 66.30 & 16.28 & 9.23 & 1.46 & $<0.01$ & 5.60 & 0.08 & 0.76 & 0.09 & 0.6 \\
$\mathrm{O}$ & 1.13 & 63.43 & 18.32 & 7.89 & 2.71 & 0.04 & 4.29 & 1.52 & 0.90 & 0.06 & 0.2 \\
$\mathrm{SRPC}$ & 60.08 & 20.13 & 4.19 & 4.44 & 0.84 & 2.47 & 1.03 & 0.21 & - & - & 2.5 \\
WPC & 49.90 & 19.31 & 5.97 & 0.30 & 2.20 & 3.13 & - & - & - & - & 6.0 \\
$\mathrm{HAPC}$ & 63.06 & 20.74 & 3.64 & 1.99 & 3.63 & 2.68 & 1.49 & 0.05 & - & - & 2.4 \\
LAPC & 61.32 & 23.53 & 2.90 & 2.97 & 3.50 & 1.73 & 0.35 & 0.14 & - & 0.14 & 2.2 \\
\hline
\end{tabular}

For this experimental design, four portland cements were used: $A$ low $C_{3} A$ portland cement (SRPC); a white portland cement (WPC); a high (HAPC) and a low (LAPC) alkali content portland cements. The chemical and physical properties are also reported in Table 1 and 2.

Table 2. Physical characteristic of calcined clays and cements

\begin{tabular}{lccccccc}
\hline \multicolumn{2}{c}{ Property / Material } & $\mathrm{R}$ & $\mathrm{O}$ & $\mathrm{SRPC}$ & WPC & HAPC & LAPC \\
\hline Density & & 2.63 & 2.65 & 3.13 & 2.95 & 3.07 & 3.14 \\
\hline Retained on & $75 \mu \mathrm{m}$ & 0.98 & 4.02 & 2.3 & 1.8 & 3.20 & 3.50 \\
sieve, \% & $45 \mu \mathrm{m}$ & 4.73 & 5.68 & 13.56 & 12.3 & 13.79 & 8.07 \\
\hline \multirow{2}{*}{ Particle size } & $\mathrm{d}_{10}, \mu \mathrm{m}$ & 1.62 & 1.29 & 3.22 & 2.57 & 3.08 & 3.29 \\
distribution & $\mathrm{d}_{50}, \mu \mathrm{m}$ & 8.76 & 7.34 & 22.37 & 12.58 & 23.99 & 21.54 \\
& $\mathrm{~d}_{90}, \mu \mathrm{m}$ & 33.65 & 36.95 & 58.44 & 32.77 & 81.88 & 60.57 \\
\hline \multicolumn{2}{r}{ Specific surface Blaine, $\mathrm{m}^{2} / \mathrm{kg}$} & 552 & 724 & 336 & 432 & 276 & 331 \\
\hline
\end{tabular}

The SRPC was used as plain PC to determine the setting time (ASTM C 191) and the amount of water required for normal consistency (ASTM C 187) of blended cements containing $20 \%$ and $40 \%$ by mass of calcined clays. The mortar flow was assessed according to ASTM C 230. At 2, 7, 28 and 90 days, the compressive strength of blended cement was assessed on three cubes (ASTM C 109).

The sulfate performance was studied using the expansion of mortar bars (ASTM C 1012) with two different portland cements: SRPC $\left(C_{3} A=3.8 \%\right)$ and WPC $\left(C_{3} A=15.31 \%\right.$ and $\left.C_{4} A F=0,91 \%\right)$. For SRPC, calcined clays were used as 20 and $40 \%$ replacement by weight and for WPC as $30 \%$ by weight. The flow of SRPC mortar ( $w / c=0.485$ and cement:graded sand $=1: 2.75)$ is determined and the water of blended cement is adjusted to obtain the same flow in SRPC-calcined clay mortars. For WPC, constant $\mathrm{w} / \mathrm{cm}$ was used in blended cements and the mortar flow was adjusted using superplasticizer. Test bars and cubes were molded according to ASTM C 157 and ASTM C 109 procedures, respectively; demolded and they were cured in lime-water at $20{ }^{\circ} \mathrm{C}$. After that mortar compressive strength reached to $20 \mathrm{MPa}$, test bars were immersed in the $\mathrm{Na}_{2} \mathrm{SO}_{4}$ solution $(0.352 \mathrm{~mol} / \mathrm{l})$ at $20^{\circ} \mathrm{C}$ with a periodically $\mathrm{pH}$-control. Measurement of length was made up to 6 months and it will be extending up to 18 months. Reported expansion is the average of six 
specimens. According to ASTM C 1157, to consider the blended cement as sulfate resistant (HS), the expansion should not exceed $0.05 \%$ at 6 months or $0.10 \%$ at 12 months.

The effectiveness of calcined clays to prevent the expansion due to the alkali-silica reaction (ASR) was tested using the ASTM C 441 procedure. Test is based on the expansion developed in mortar bars made with $\operatorname{HAPC}\left(1.03 \% \mathrm{Na}_{2} \mathrm{O}_{\text {eq }}\right)$ and $25 \%$ of calcined clay using Pyrex ${ }^{\circledR}$ glass aggregate and stored in container at $38^{\circ} \mathrm{C}$ according to ASTM C 227. According to ASTM C 441, the pozzolan effectiveness is measured as the reduction of mortar expansion with calcined clay related to the expansion of mortar bars with HAPC at 14 days. To compare the effectiveness of calcined clay to mitigate the ASR a LAPC $\left(0.37 \% \mathrm{Na}_{2} \mathrm{O}_{\text {eq }}\right)$ was tested. As suggest the ASTM C 311 , the combination of LAPC with calcined clays will not cause an increase of expansion due to their high alkali content $(5.65$ and $5.29 \% \mathrm{Na}_{2} \mathrm{O}_{\text {eq }}$ for $\mathrm{R}$ and $\mathrm{O}$, respectively). For blended cements, ASTM 1157 standard establishes that the expansion should not exceed the limit of $0.02 \%$ at 14 days and $0.06 \%$ at 56 days to be considered as Low reactivity with alkali-reactive aggregates (option R).

\section{Results}

\subsection{Setting time and water demand}

The time of setting and the water requirement for normal consistency are presented in Table 3. About setting time, one of the illite calcined clay $(\mathrm{N})$ presents stimulation in the beginning of setting, in both replacement percentages. On the other hand, all blended cements delay the final setting time compared with control cement. Water demand of SRPC was similar to SRPC $+20 \% O$ and SRPC $+40 \% O$ pastes, and it was slightly high ( 7\%) for SRPC+20\%R and SRPC+40\%R pastes.

\begin{tabular}{ccccccc}
\hline \multicolumn{7}{c}{ Table 3. Setting time and water demand. } \\
\hline \multicolumn{2}{c}{ Blended cement } & SRPC & SRPC+20\%R & SRPC+40\%R & SRPC+20\%O & SRPC+40\%O \\
\hline Setting time & Initial & 162 & 168 & 182 & 119 & 94 \\
(min) & Final & 430 & 490 & 526 & 452 & 497 \\
\hline \multicolumn{2}{l}{ Water demand (\%) } & 27.0 & 28.5 & 29.8 & 27.3 & 27.6 \\
\hline
\end{tabular}

\subsection{Flow and compressive strength}

The control mortar (SRPC) has a flow of $80 \%$ and the mortars with 20 and $40 \%$ R showed a flow comparable with that control with better water retention. Mortars made with 20 and $40 \% \mathrm{O}$ have a low flow (50\%) and the w/cm was increased up to 0.60 to reach the same flow in $20 \%$ O-SRPC mortar.

Fig. 1 shows the compressive strength for all mortars. At 2 days, the strength of all blended cements is lower than the corresponding to control mortar. For R calcined clays, the $20 \%$ of replacement reaches the strength of control at 7 days and the $40 \%$ replacement reaches to $87 \%$ of the control. On the other hand, mortars with 20 and $40 \% 0$ do not exceed the $70 \%$ of the control strength. At 28 days, both mortars with R calcined clay maintain strength level of control, while SRPC $+20 \% O$ and SRPC $+40 \% 0$ reach to 95 and $84 \%$ of control's strength. At 90 days, mortars with R clays reach to comparable strength (1.05 and 0.94) of SRPC mortar. On contrary, the strength developed is lower for mortars with $\mathrm{O}$ calcined clays reaching to 0.70 and $0.82 \%$ due to the large water requirements that increase the $\mathrm{w} / \mathrm{cm}$. Red calcined clay $(\mathrm{R})$ has a very good pozzolanic activity and mortars develop a similar compressive strength than the control mortar. However, the orange calcined clay (O) presents some incomplete transformation causing the stimulation of portland cement hydration at early ages. But, the progress of pozzolanic reaction is limited causing low strength at later ages. 


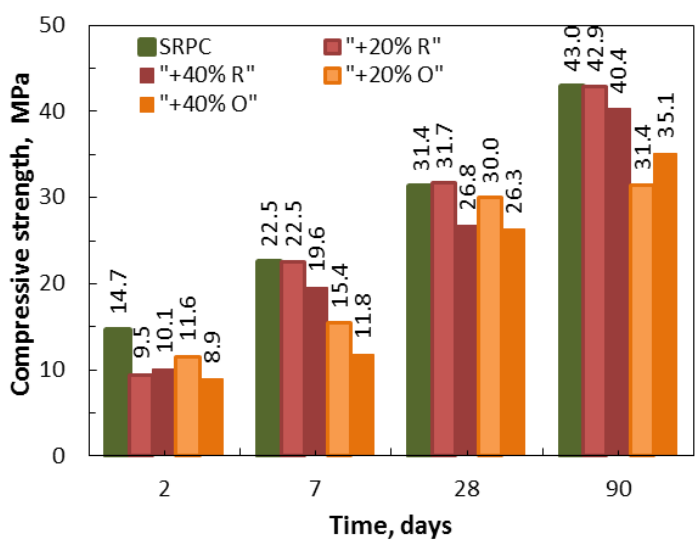

Figure 1: Compressive strength of plain and blended cements

\subsection{Sulfate performance}

Expansion of mortar prisms in sulfate solution are shown in Fig. 2. For SRPC (Fig 2a), it's can be observed that expansion is too low until 28 days and then the expansion increases with uniform rate up to six months attaining to $0.059 \%$. This value is higher than the limit to considerer it as HS cements according to the criterion of ASTM C 1157. It is attributed to the high level of $\mathrm{C}_{3} \mathrm{~S}$ in the SRPC that could cause fails for this type of test under controlled $\mathrm{pH}$ [7]. Compared with control mortar, the replacement of SRPC by R calcined clay produces slight increases of initial expansion up to 56 days.

Then, the expansion develops low to null rate of expansion for $20 \%$ and $40 \% \mathrm{R}$ replacements.

At 6 months, both blended cements have lower $(0.03 \%$ and $0.01 \%)$ expansion than limit $(0.05 \%)$ and it could be considered as high sulfate-resistant (HS). SRPC $+20 \% 0$ shows a worse performance than the corresponding to SRPC and the expansion limit (0.100 \%) is surpassed after 150 days instead of the low $\mathrm{C}_{3} \mathrm{~A}$-content in this cement. It can be attributed to the increase of $\mathrm{w} / \mathrm{mc}$ to obtain the flow and consequently the open porosity to sulfates. On the other hand, the SRPC $+40 \% \mathrm{O}$ has lower expansion than the control bars attaining to $0.04 \%$ at 6 months.

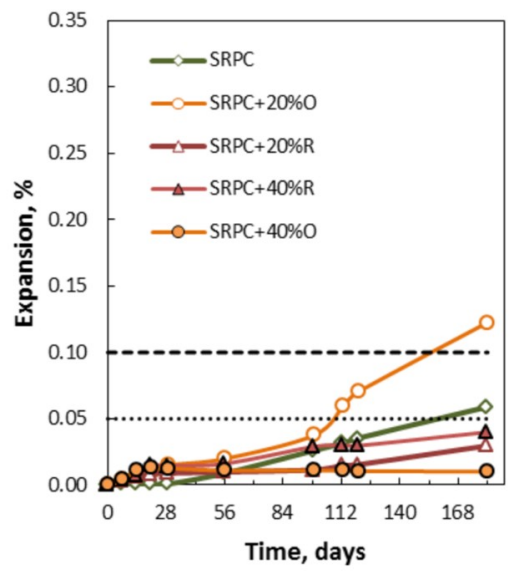

a)

Figure 2. Sulfate expansion: (a) Low $\mathrm{C}_{3} \mathrm{~A}$ cement (SRPC); B) White portland cement (WPC)

Fig. $2 \mathrm{~b}$ shows the expansion of mortars bars with WPC. Control mortar has a very quick expansion development after 28 days with exponential rate attaining to failure limit $(0.10 \%)$ before than 56 days. Conversely, both blended cements present a very low rate of expansions during the six months reported attaining to expansion of $0.018 \%$ that is lower than limit to classify as HS.

\subsection{ASR expansion}

Fig. 3 shows the expansion for mortar bars tested with high and low alkali portland cements and with blended cements containing $25 \%$ of $\mathrm{R}$ or $\mathrm{O}$ calcined illite clay up to 90 days. For high alkali cement (Fig 3a), the control bars has $0.221 \%$ of expansion at 14 days that is lower than the least value $(0.2 \%)$ required by the ASTM C 1157 . The bars with calcined clays attains to $0.045 \%$ and $0.040 \%$ for $R$ and 0 , respectively. For these values, the effectiveness of expansion reduction of illitic calcined clay was 79.6 and $81.8 \%$ for $R$ and $O$, respectively. The expansion of control was increased until 28 days and then it has a slowly rate indicating the compsumtion of free alkalis in mortar. On the other hand, mortar bars with calcined clays has a very slow increase attaining to 0.057 and $0.048 \%$ at 56 days for 
$\mathrm{R}$ and $\mathrm{O}$ pozzolans, respectively. It can be attributed that pozzolan do not provide alkalis to the progress of ASR. Although the expansion are not sufficient to consider these blended cements as ASR resistant, because they exceed the expansion limits of $0.02 \%$ at 14 days when the slow pozzolanic reaction begins.

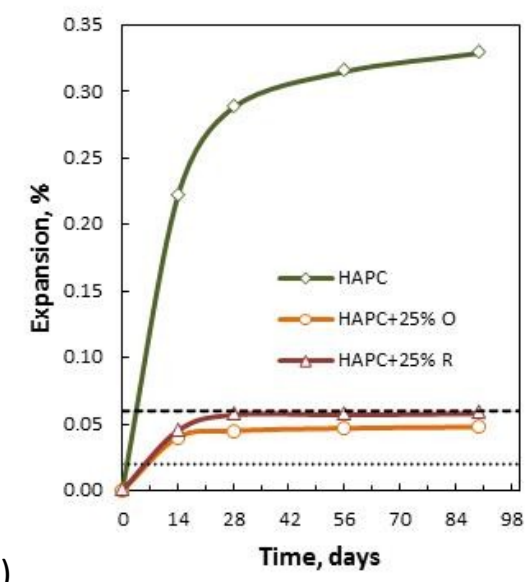

Figure 3: Expansion due ASR for mortar bars tested with: a) high alkali PC and b) low alkali PC

\section{Conclusions}

Preliminary laboratory test showed that the replacement of calcined illitic clays lead to obtain blended cement with similar final strength than the portland cement with low water demand

At six months, illitic clays blended cements with $w / c<0.50$, can be considered as high sulfate resistance cements. Sulfate performance of mortars containing $20 \%$ of illitic calcined clay was worsened when the water demand increases the $\mathrm{w} / \mathrm{cm}$ of mortar.

The addition of $25 \%$ of illitic calcined clay may decrease the ASR expansion for high alkali portland cement, but their performance at 14 days is worst that the obtained by low alkali portland cement. Although, the expansion obtained are not sufficient to consider the blende cement as inhibitor of ASR. Long time performance test with reactive aggregates will be conclusive. The illitic calcined clay can impair the ASR performance of low alkali portland cement.

\section{References}

[1] R. Lemma, E.F. Irassar \& V. Rahhal, Calcined illitic clays as portland cement replacements. In K.Scrivener \& A. Favier (Eds.), Calcined Clays for Sustainable Concrete (2015) 269-276. DOI: 10.1007/978-94-017-9939-3_33

[2] V. S. Ramachandran, Concrete Admixtures Handbook: Properties, Science and Technology. 2nd ed, ed. V.S. Ramachandran. United States of America: Noyer Publication (1995)

[3] C. Li, J.H. Ideker \& T. Drimalas, The efficacy of calcined clays on mitigating alakli-silica reaction (ASR) in mortar and its influence on microstructure. In K.Scrivener \& A. Favier (Eds.), Calcined Clays for Sustainable Concrete (2015) 211-217. DOI: 10.1007/978-94-017-9939-3_26

[4] A. Trümer \& H.M. Ludwig, Sulphate and ASR Resistance of Concrete Made with Calcined Clay Blended Cements. In Karen Scrivener \& Aurélie Favier (Eds.), Calcined Clays for Sustainable Concrete (2015) 3-9. DOI: 10.1007/978-94-017-9939-3_1

[5] T. Ramlochan, M. Thomas \& K.A. Gruber, The effect of metakaolin on alkali-silica reaction in concrete. Cem. Concr. Res. 30 (2000) 339-344.

[6] S. Wild, J.M. Khatib, \& M. O'Farrell, Sulphate resistance of mortar, containing ground brick clay calcined at different temperatures. Cem. Concr. Res. 27 (1997) 697-709.

DOI: http://dx.doi.org/10.1016/S0008-8846(97)00059-8

[7] M.A. Gonzalez \& E.F: Irassar, Ettringite Formation in low $\mathrm{C}_{3}$ A Portland Cement Exposed to Sodium Sulphate Solution, Cem. Concr. Res. 27(1997) 1061-1072. DOI: 10.1016/S0008-8846(97)00093-8 